\title{
THE ROUTINE TREATMENT OF EARLY SYPHILIS
}

\section{SOME RESULTS FROM A PROVINCIAL CLINIC}

By P. C. P. INGRAM, M.B., B.S., Lond., Hon. Physician for Diseases of the Skin and M.O. in charge V.D. Clinics, Royal Gwent Hospital, Newport, Mon.

THE papers by Watson ${ }^{1}$ and Harrison ${ }^{2}$ have again raised in my mind the question as to the amount of arsenobenzol compound which should be considered necessary to complete a cure in a case of early syphilis, and, while the exhaustive paper by Harrison ${ }^{3}$ (for which over 3,500 case records were examined) might be considered to go a long way towards settling the question, there appears still to be a good deal of difference of opinion among medical officers of experience.

It occurred to me, therefore, that it might be interesting to see what have been the results of treatment in the clinic of which I have had charge for the past twelve years, where a routine course of treatment, based largely on the suggestions of Harrison ${ }^{4}$ some years ago, was adopted, and not, subsequently, as far as arsenobenzol compounds were concerned, substantially altered.

The clinic is a department of a provincial general hospital which serves an industrial town and large seaport and a surrounding, largely industrial, but partly agricultural, district, the whole having a population of approximately a quarter of a million.

The records of the male cases of primary and secondary syphilis which commenced treatment in the clinic in the years I924 to 1927 inclusive have been analysed with the results shown below.

The routine treatment of men of average weight and constitution consisted of two courses of injections of arsenobenzene compounds with an interval of four weeks between the courses. Each course consisted of nine injections (three of 9I4 and six of stabilarsan) at weekly intervals, the first dose being $0.45 \mathrm{grm}$. and the remainder 


\section{BRITISH JOURNAL OF VENEREAL DISEASES}

$0.6 \mathrm{grm}$., unless there was any indication for reduction. On the day of each arsenical injection $0.2 \mathrm{grm}$. bismuth (gr. I Hg in the early months of I924) was also injected. In the interval between the courses potassium iodide was administered in doses increasing from gr. Io to gr. 20 t.i.d.

In each case of primary syphilis an examination was made for $S$. pallida, and in all cases a Wassermann test of the blood was carried out. In those in which the blood proved negative a second test was made at the end of the first week. Subsequently blood tests were carried out at the end of the first and second courses respectively. After this, if the blood was negative, treatment was suspended and blood tests were carried out, first at one, two and three-monthly intervals, and then at threemonthly intervals (each of these tests being preceded by a provocative injection of an arsenobenzene compound), until the blood had been negative for two years.

The results were as follows :-

Total cases of early syphilis, 254 (I82 primary and 72 secondary). Of these, $7 \mathrm{I}$ completed two courses and were observed subsequently for periods ranging from six months to four years; the remainder did not complete the treatment and observation, though a further 29 completed the two courses; some observations on these follow the analysis of the $7 \mathrm{r}$.

The $7 \mathrm{I}$ cases are divided into 39 which received $9 \mathrm{grm}$. or more arsenobenzene compounds, 30 which received $4^{\circ} 05$ to 9 grm., and 2 which received less than $4^{\circ} .05 \mathrm{grm}$.

Of these 2 , both had defaulted after five injections of $0.45 \mathrm{grm}$. at weekly intervals, and both were negative when seen twenty-two and ten months respectively after the last treatment.

Of the 30 who had received 4.05 to 9 grm. arsenobenzene compounds within three months of commencing treatment, 9 were originally sero-negative primary cases (S. pallida present) and were negative from one to more than two years after treatment ( 6 from one to two years ; 3 for two or more years).

Twenty-one were originally sero-positive, and 20 of these were negative after the course. The single positive case was not seen again for five years, when his blood serum was negative; a result repeated after a provocative injection. None of the 20 relapsed either clinically or serologically within periods of observation of six to 


\section{ROUTINE TREATMENT OF EARLY SYPHILIS}

twelve months in 3 ; over one and less than two years in 6 , and two or more years in II.

Of the 39 who had two courses (9 or more grm. arsenobenzene compounds within six months of commencing treatment), 8 were originally sero-negative primary cases (S. pallida present) and remained negative during periods of observation of over six but less than twelve months in I ; over one but less than two years in 4 , and two or more years in 3 .

Thirty-one were originally sero-positive cases, and 22 became negative by the end of the first course, and 8 more by the end of the second course, I remaining doubtful.

Those completely negative at the end of the second course remained so during periods of observation of more than six months but less than twelve, in I2 cases; one year but less than two in 7 , and two years or more in II.

The case which was doubtful had received only six injections of the first course when an injury prevented his return for three months, after which he received three further injections before his blood was tested and found to be strongly positive. After the second course he was absent for three months, and was found to have relapsed from doubtful to strongly positive. Three further courses were necessary to reduce the reaction to negative, after which he remained so during a period of observation lasting fourteen months.

Of the remaining 183 cases, 46 were given transfer books for other clinics, 29 completed the two courses, 48 defaulted after one course, and 60 without completing one course.

Of these it may be noted that 27 completed two courses of arsenobenzene and bismuth in less than eleven months, and in only I was the blood still positive, whereas in those who took longer to complete two courses there were no less than 6 . Of the 48 who defaulted after one course, in those who completed it in under three months, all the original sero-negatives were negative, and 18 out of the original sero-positives; of those who took over three months, I sero-negative was positive (he had an interval of seven months between his first and second injection) and I 3 out of the I4 sero-positives had become negative.

It will therefore be seen that out of 208 cases of early syphilis (254 less 48 transfers of which the majority were seamen who had only one or two injections) only 28 


\section{BRITISH JOURNAL OF VENEREAL DISEASES}

completed the Tests for Cure suggested in the Ministry of Health's Memorandum V., 2I, rather more than I in 8.

In a further 4I, however, the blood was negative to tests taken at repeated intervals of from six months to one year and eleven months after all treatment was stopped ; I5 more had two courses of injections followed by a negative blood, and a further $3 \mathrm{I}$ had received sufficient treatment to produce not only freedom from clinical signs, but also a negative Wassermann; this accounts for rather more than half the early cases. It is, of course, impossible to say how many of the 87 cases just mentioned were cured, but the treatment appears to me to have some bearing on the striking fall in the number of new cases of syphilis which has been noticed in the clinic during the past ten years.

In the four years preceding the period under review the number of cases of syphilis in all stages dealt with for the first time was I,34I ; in the four years under review it was 696 ; and in the succeeding four years the total had fallen to 463 .

It might be interesting to note that the number of new cases of gonorrhœa in these periods were I,I I I, I,205 and I,II2.

I am indebted to Mr. P. Spencer, one of the male nurses, for sorting the case cards, and for the preliminary figures, which has necessitated a good deal of careful work. During my absence on holiday the work of the clinic was done by my colleague, Dr. Acomb, whose ample notes have enabled a continuous record to be kept.

\section{REFERENCES}

(I) Watson : Brit. Jour. V.D., October, I93I, VII., p. 276.

(2) HARRISON : Brit. Jour. V.D., January, r932, VIII., p. 48.

(3) HARrison: Special Report Series, No. I32, H.M.S.O.

(4) HARRISON : "Diagnosis and Treatment of V.D.," London. 